\title{
Relationship between Na layer and CNA variations observed at Syowa, Antarctic
}

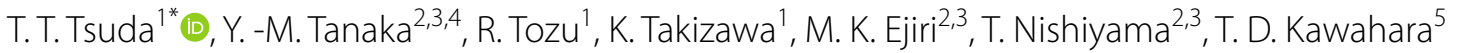 \\ and T. Nakamura ${ }^{2,3}$
}

\begin{abstract}
We have performed a statistical data analysis on relationship between simultaneous Na density data and cosmic noise absorption (CNA) data, which is an indicator for energetic particle precipitation, obtained at Syowa, Antarctic in 2000-2002. It is found that the Na densities around the topside of Na layers (above $\sim 95 \mathrm{~km}$ height) tended to be smaller when the CNA was larger. The amounts of Na density responses, i.e., Na density decrease or Na loss, were increasing with magnetic local time (MLT) from dusk hours to dawn hours, and those of CNA responses, i.e., CNA increase, were also increasing with MLT. Thus, there were clear negative correlations between the Na density and CNA variations. These results indicate that the Na loss around the topside of Na layer would be induced by the energetic particle precipitation, and its effect would be more severe in dawn hours.
\end{abstract}

Keywords: Na layer, CNA, Energetic particle precipitation, Geomagnetic activity, Polar region, Syowa

\section{Introduction}

The sodium $(\mathrm{Na})$ layer around $80-110-\mathrm{km}$ heights is one of the metal layers existing in the Earth's upper atmosphere, and has been widely used as a valuable observation target to study the upper atmospheric science using the lidar technique (cf. Chu and Papen 2005, and references therein). The height range, i.e., $80-110-\mathrm{km}$ heights, is corresponding to the mesosphere and lower thermosphere as well as the ionospheric $D$ and $E$ regions. At high latitudes, energetic particles precipitating from the magnetosphere can often penetrate into the $E$ region and even into the $D$ region. For example, electrons with energy of $20 \mathrm{keV}$ can penetrate into $\sim 90 \mathrm{~km}$ height (cf. Turunen et al. 2009). Thus, the influence of energetic particles on the $\mathrm{Na}$ layer is of interest regarding changes in atmospheric composition accompanied by auroral or geomagnetic activity.

There have been several previous investigations related with this issue (von Zahn et al. 1987; Nomura et al. 1987;

\footnotetext{
*Correspondence: takuo.tsuda@uec.ac.jp

${ }^{1}$ Department of Computer and Network Engineering, University

of Electro-Communications (UEC), Chofu, Japan

Full list of author information is available at the end of the article
}

$\mathrm{Gu}$ et al. 1995; Heinselman et al. 1998; Heinselman 2000; Tsuda et al. 2013; Takahashi et al. 2017; Tsuda et al. 2017). In most of them, event-based investigations (without statistical dataset) were performed, and those reported conflicting results and/or suggestions regarding the response in the Na density to auroral activity. In some cases, the Na density increased (von Zahn et al. 1987; Gu et al. 1995), and in others, it decreased (Nomura et al. 1987; Heinselman et al. 1998; Heinselman 2000; Tsuda et al. 2013; Takahashi et al. 2017).

Contrary to those works, Tsuda et al. (2017) made a statistical investigation on the global response in the $\mathrm{Na}$ layer to geomagnetic activity using $\mathrm{Na}$ density data from 2004 to 2010 obtained using the Optical Spectrograph and Infrared Imager System (OSIRIS) on board the Odin satellite. As the results, they found a significant decrease in the $\mathrm{Na}$ density above $\sim 95 \mathrm{~km}$ height in both the southern and northern polar regions during the geomagnetically active periods. The reason for the $\mathrm{Na}$ density decrease is considered to be as follows (cf. Heinselman 2000; Takahashi et al. 2017, and references therein). First, ionization by energetic particles related with geomagnetical activity can produce $\mathrm{NO}^{+}$and $\mathrm{O}_{2}^{+}$ions. Then, the following charge transfer reactions, namely, 
$\mathrm{Na}+\mathrm{NO}^{+} \rightarrow \mathrm{Na}^{+}+\mathrm{NO}$ and $\mathrm{Na}+\mathrm{O}_{2}^{+} \rightarrow \mathrm{Na}^{+}+\mathrm{O}_{2}$, can lead to the loss of $\mathrm{Na}$ and at the same time the generation of $\mathrm{Na}^{+}$. In this way, it is considered that the energetic particles can be an important factor to induce such Na-layer variations.

Furthermore, the reason why there was no significant $\mathrm{Na}$ decrease below $\sim 95 \mathrm{~km}$ can be explained by considering shorter lifetimes of $\mathrm{Na}^{+}$at lower heights (Tsuda et al. 2017). As mentioned above, the Na decrease and $\mathrm{Na}^{+}$increase can be induced at the same time due to the charge transfer reactions with the enhanced ionization (cf. Heinselman 2000; Takahashi et al. 2017). After that, the produced $\mathrm{Na}^{+}$can be converted back to $\mathrm{Na}$ with the $\mathrm{Na}^{+}$lifetime, which is generally shorter at lower heights, e.g., $10^{2} \mathrm{~s}$ at $90 \mathrm{~km}, 10^{3} \mathrm{~s}$ at $95 \mathrm{~km}$, and $10^{4} \mathrm{~s}$ at $100 \mathrm{~km}$ (cf. Matuura et al. 2013). Thus, at lower heights, the decrease in the Na density can be more limited.

In the present study, we perform a statistical analysis on such $\mathrm{Na}$ layer responses using $\mathrm{Na}$ density data, together with cosmic noise absorption (CNA) data. Those data were obtained from simultaneous observations at Syowa, Antarctic $\left(69.0^{\circ} \mathrm{S}, 39.6^{\circ} \mathrm{E}\right)$. Utilizing the ground-based observational data, we can investigate local-time characteristics in the Na-layer response for the first time. It should be noted that it was difficult to see such local-time variations in the Na-layer response from the statistical investigation by Tsuda et al. (2017) because of the dataset obtained from the polar orbit satellite, Odin.

\section{Data}

\section{Na density}

$\mathrm{Na}$ lidar observations were carried out, as a part of the Japanese Antarctic Research Expedition (JARE) observations, at Syowa $\left(69.0^{\circ} \mathrm{S}, 39.6^{\circ} \mathrm{E}\right)$ in Antarctica between 2000 and 2002 (cf. Kawahara et al. 2002, 2004, 2011). In this laser remote sensing, laser pulses tuned to the $\mathrm{Na}_{2}$ line $(589 \mathrm{~nm})$ were transmitted vertically, and it induced $\mathrm{Na}$ resonance scattering in Na layers above Syowa. The scattering signals were collected with the telescope, and then detected with the photomultiplier tube (PMT) through the optical system including the narrowband filter. The regular operations with the two-frequency technique (cf. She et al. 1990) provided neutral temperature and $\mathrm{Na}$ density data. The accumulated dataset in 2000-2002 consists of 254 nights. In the present analysis, we used $\mathrm{Na}$ density data, derived from 12-min and 2-km integration, of the whole nights, i.e., 254 nights. Thus, the time and height resolutions of the Na density data were $12 \mathrm{~min}$ and $2 \mathrm{~km}$, respectively.

\section{CNA}

CNA is an absorption of cosmic radio noise in the ionospheric $D$ region, which is caused by the ionospheric electron density enhancement due to energetic particle precipitation. Thus, CNA data can be used as a proxy for energetic particle precipitation into the $D$ region, and it were obtained from the imaging riometer with an $8 \times 8$ dipole antenna array at Syowa (cf. Yamagishi et al. 2000). The observations provided CNA data for $8 \times 8$ beams in an area of about $200-\mathrm{km} \times 200-\mathrm{km}$ at an altitude of $90 \mathrm{~km}$. The observation frequency was $30 \mathrm{MHz}$, and the data sampling rate was $1 \mathrm{~Hz}$. Precipitation of 10-100$\mathrm{keV}$ electrons into $80-100-\mathrm{km}$ heights could be mainly monitored by the CNA observations. For comparisons with the Na density data, we selected CNA data from a single direction, which was a near-vertical direction, during the same days as the $\mathrm{Na}$ density data, i.e., 254 days in total. Here, the center of 24-h data for each day was set to the local midnight at Syowa, i.e., 00:00 local time (LT) $=$ 21:00 magnetic local time $(\mathrm{MLT})=21: 00$ universal time (UT). Then, 12-min averaged CNA data were calculated to fit the time resolution of the $\mathrm{Na}$ density data.

\section{Results}

\section{Direct comparison between Na density and CNA}

Figure 1a shows a comparison between simultaneous $\mathrm{Na}$ density data at $105 \mathrm{~km}$ and CNA data, as an example. It seems that there was a large variability, and its correlation coefficient $(C C)$ was very small $(-0.065)$. This would be mainly due to large variations in the Na density, which may be due to seasonal, day-to-day, diurnal, and other variations. In addition, the narrow lidar beam, compared with the wide riometer beam, may contribute to the large variability to some extent. We may see a tendency that $\mathrm{Na}$ densities were lower $\left(<1.5 \times 10^{8} \mathrm{~m}^{-3}\right)$ when CNA was larger $(>1.5 \mathrm{~dB})$, while the number of data for such larger CNA may not be enough.

Here, to see in more detail, we separated data into two groups based on CNA values. One is CNA of $0-0.25 \mathrm{~dB}$, which corresponds to a quiet condition. The other is CNA of $0.25-2 \mathrm{~dB}$, which corresponds to an active condition. The total number of data points for the quiet condition was 3148, and that for the active condition was 2847. We counted numbers of data points for each bin in the $\mathrm{Na}$ density for each group, and then normalized it with the total numbers of data points for each group. After that, we applied fittings with the lease-squares method assuming a log-normal distribution $\left(f_{(x)}=\frac{A}{\sqrt{2 \pi} \sigma x} \exp \left(-\frac{(\ln x-\mu)^{2}}{2 \sigma^{2}}\right)\right)$. In this way, we obtained probability density functions (PDFs) for the two groups, as shown in Figs. 1b and c. The median $\left(\mathrm{e}^{\mu}\right)$ of PDF for the quiet condition was $1.8 \times 10^{8} \pm 1.2 \times 10^{7} \mathrm{~m}^{-3}$, and that for the active condition was $1.4 \times 10^{8} \pm 5.9 \times 10^{6} \mathrm{~m}^{-3}$. Thus, there was a significant difference between them, and the median $\mathrm{Na}$ density for the active condition was smaller. The mode 


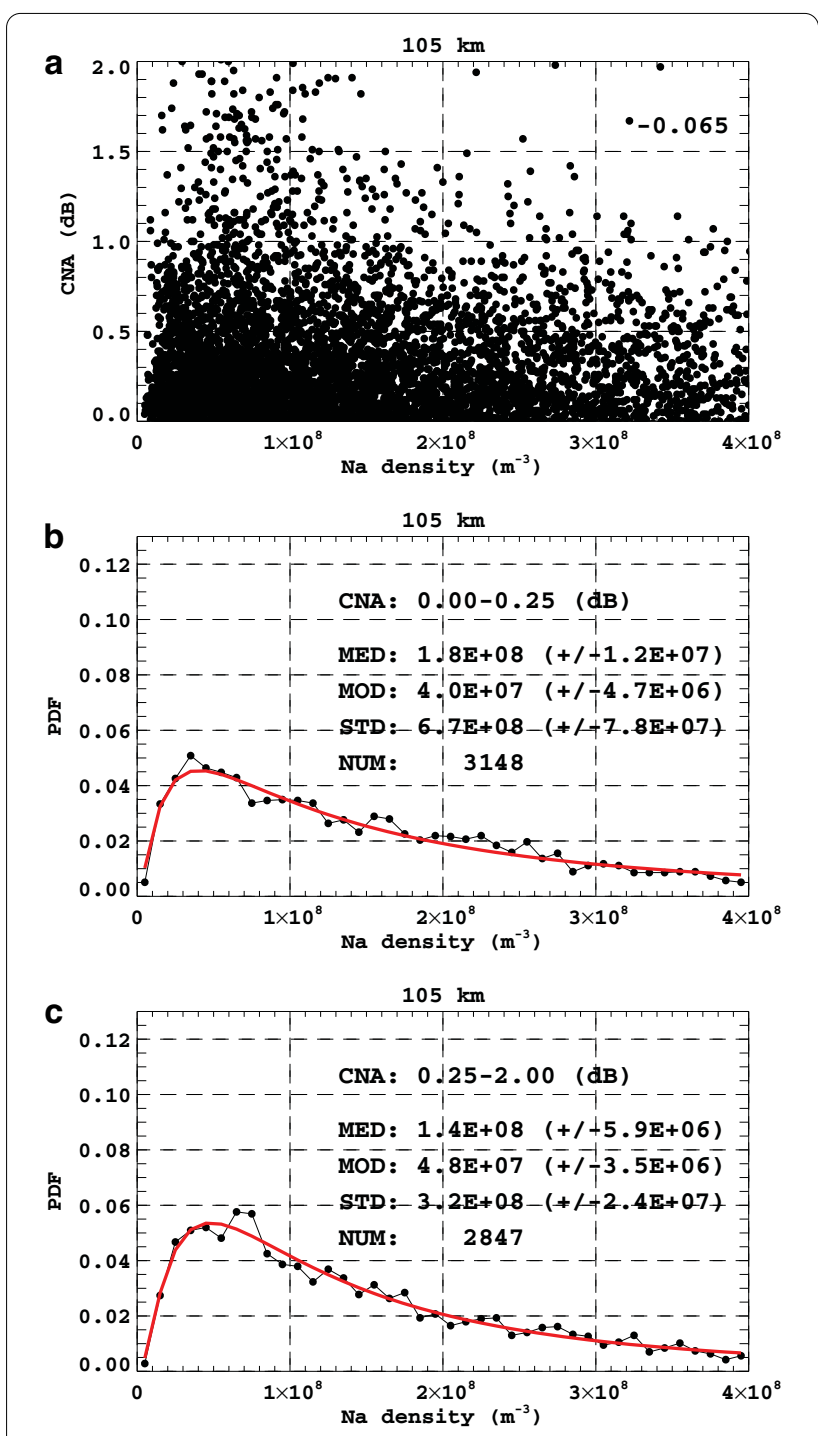

Fig. 1 a Comparison between Na density at $105 \mathrm{~km}$ and CNA, and its correlation coefficient is also shown in the figure. $\mathbf{b}$ Probability density function (PDF) of Na density at $105 \mathrm{~km}$ for CNA of 0-0.25 dB (quiet). Black shows data from observations, and red shows a fitted PDF with a least-squares method. Derived parameters of the fitted PDF are also shown in the figure. $\mathbf{c}$ Same as $\mathbf{b}$ but for CNA of $0.25-2 \mathrm{~dB}$ (active) $\left(\mathrm{e}^{\mu-\sigma^{2}}\right)$ for the quiet condition was $4.0 \times 10^{7} \pm 4.7 \times 10^{6} \mathrm{~m}^{-3}$, and that for the active condition was $4.8 \times 10^{7} \pm 3.5 \times 10^{6} \mathrm{~m}^{-3}$. Thus, the difference between them was not so clear. The standard deviation $\left(\sqrt{\mathrm{e}^{2 \mu+\sigma^{2}}\left(\mathrm{e}^{\sigma^{2}}-1\right)}\right)$ for the quiet condition was $6.7 \times 10^{8} \pm 7.8 \times 10^{7} \mathrm{~m}^{-3}$, and that for the active condition was $3.2 \times 10^{8} \pm 2.4 \times 10^{7} \mathrm{~m}^{-3}$. Thus, there was a significant difference between them, and the standard deviation for the active condition was smaller.
We did same data processing for $\mathrm{Na}$ density data from 85 to $105 \mathrm{~km}$, and then the obtained median values of PDFs are shown in Fig. 2a. Also, the deviation between the median values $\left(\frac{\mathrm{Na}_{\text {active }}-\mathrm{Na}_{\text {quiet }}}{\mathrm{Na}_{\text {quiet }}} \times 100(\%)\right)$, where $\mathrm{Na}_{\text {active }}$ is the median $\mathrm{Na}$ density during the active condition, and $\mathrm{Na}_{\text {quiet }}$ is the median $\mathrm{Na}$ density during the quiet condition, are shown in Fig. $2 \mathrm{~b}$. The results at 95-105 km were basically similar to those at $105 \mathrm{~km}$, which is mentioned in the previous paragraph (see Fig. 1), and thus, it is found that the median values above $95 \mathrm{~km}$ for the active condition were significantly smaller than those for the quiet condition. The deviations above $95 \mathrm{~km}$ correspond to $10-20 \%$ decreases (i.e., -10 to $-20 \%)$ in the Na density.

\section{MLT characteristics}

For investigation on the MLT characteristics, we used 3-h ap indices which indicate geomagnetical or auroral activity. In similar way as the CNA data, we selected ap indices during the 254 days and calculated 24-h averaged ap index from 09:00 MLT to 09:00 MLT, i.e., the center of time interval was set to the local midnight, 00:00 LT = 21:00 MLT $=21: 00$ UT. It should be noted that the calculated daily averaged ap index is different from the normal daily averaged ap index, Ap index, which is the averaged ap indices from 00:00 UT to 24:00 UT. We defined quiet days as days with the daily averaged ap index of $<10$, and active days as days with that of $\geq 10$. Thus, we categorized the $\mathrm{Na}$ density and CNA data into data of 153 quiet days and data of 101 active days.

To see statistical features, we calculated median values from the datasets at each time and height for each activity level. Figure 3 shows MLT-height variations in the median $\mathrm{Na}$ densities during the quiet and active days. It should be noted that the data coverages were limited during nighttime (14:00-30:00 MLT) because of the Na lidar observations during dark sky. In both the quiet and active days, Na layers were distributed at $80-105-\mathrm{km}$ heights, and its density peaks were located at $\sim 90 \mathrm{~km}$ height. Overall, it seems that there was no big difference between the median $\mathrm{Na}$ densities during the quiet and active days, but we can see some slight differences around the topside of Na layers ( $\sim 100 \mathrm{~km}$ height). At $\sim 100 \mathrm{~km}$ height, the median $\mathrm{Na}$ densities during the active days were a bit smaller than those during the quiet days.

For more detailed inspection, Fig. 4 shows MLT variations of the Na densities at 97-103-km heights during the quiet and active days, together with the CNA variation. Variations of $\mathrm{Na}$ densities and CNA of each day were quite large, which may be due to seasonal, day-to-day, diurnal, and other variations. Here, we investigate statistical features utilizing median values during the quiet and active days. At 103-km height, median Na densities 

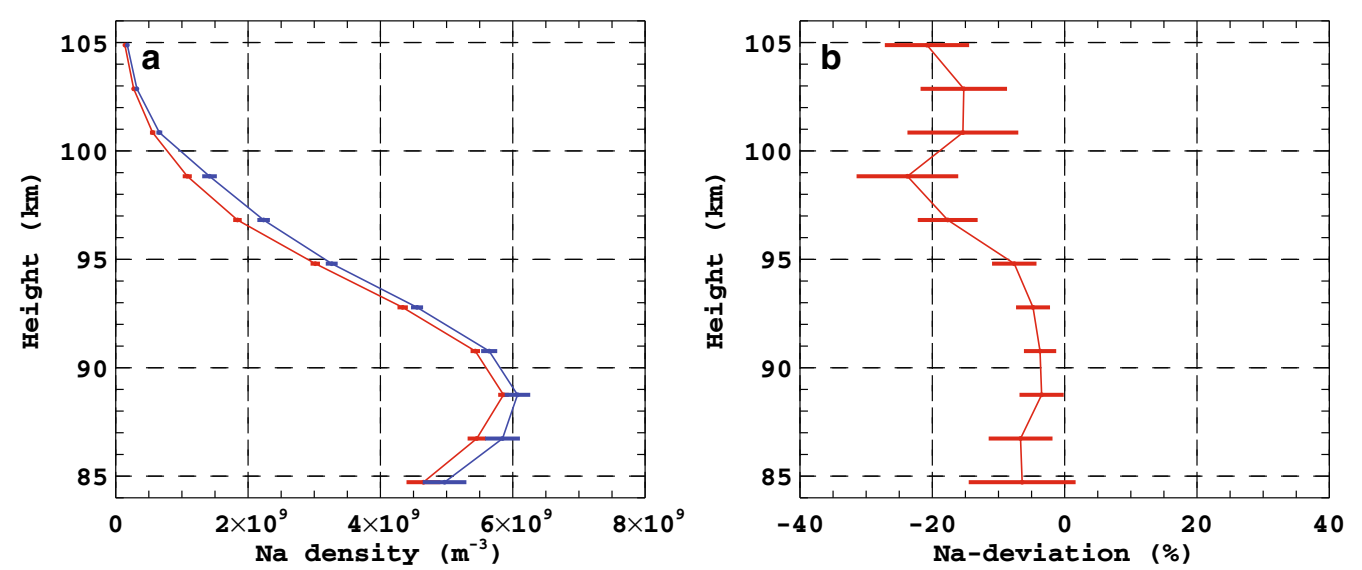

Fig. 2 a Median values in the fitted PDF of the Na densities from 85 to $105 \mathrm{~km}$ for CNA of 0-0.25 dB (blue) and CNA of 0.25-2 dB (red). b Deviation between the median values for CNA of 0-0.25 dB (quiet) and CNA of 0.25-2 dB (active) which are shown in $\mathbf{a}$. The horizontal error vars correspond to $\pm 1 \sigma$
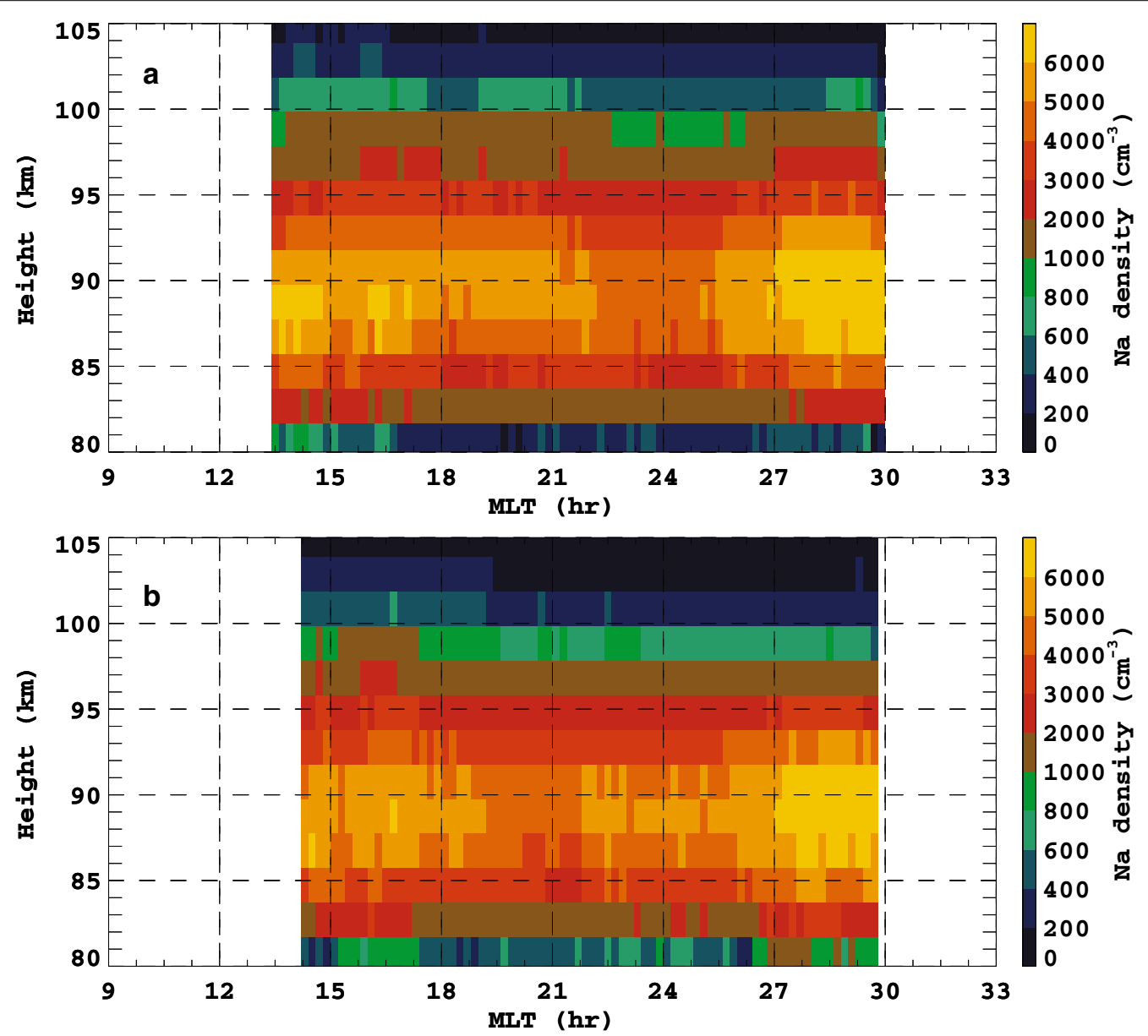

Fig. 3 MLT-height variations in the median Na densities during a the quiet days (the daily averaged ap $<10$ ) and $\mathbf{b}$ the active days (the daily averaged $a p \geq 10$ ) 

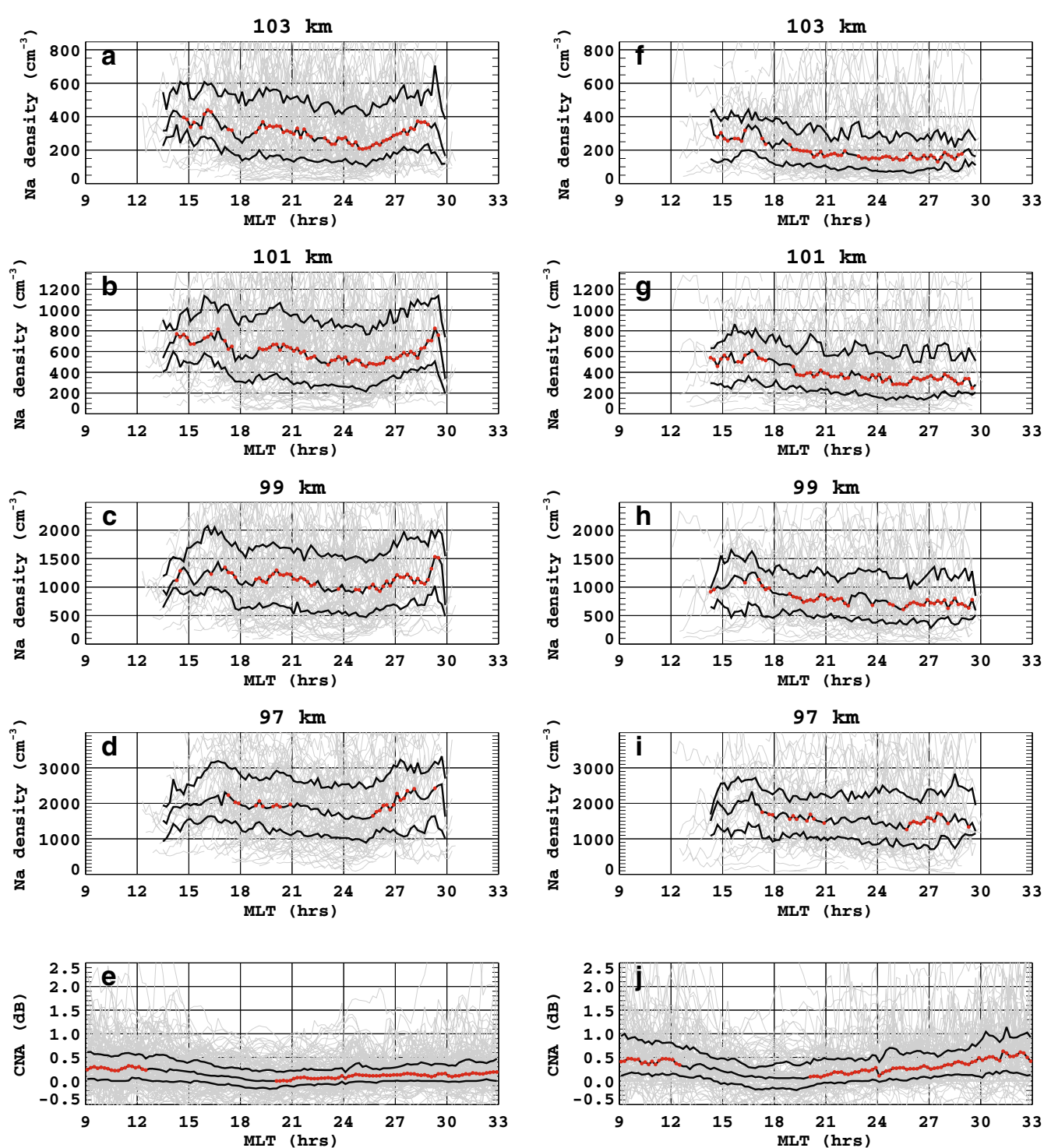

Fig. 4 a-d MLT variations in the Na densities at 97-103-km heights during the quiet days (the daily averaged ap < 10). e MLT variation in the CNA during the quiet days. $\mathbf{f}-\mathbf{i}$ Same as $\mathbf{a}-\mathbf{d}$, but for the active days (the daily averaged ap $\geq 10$ ). j Same as $\mathbf{e}$, but for the active days. Light gray lines show variations on each day. Black lines show median values, and lower and upper quantile values of each dataset. Red points indicate data which have significant differences (> 98\% probability) in the median values between the quiet and active days

during the active days were $\sim 300 \mathrm{~cm}^{-3}$ at $\sim 15: 00$ MLT and $\sim 150 \mathrm{~cm}^{-3}$ at $\sim 24: 00 \mathrm{MLT}$, and those during the quiet days were $\sim 400 \mathrm{~cm}^{-3}$ at $\sim 15: 00$ MLT and $\sim 250 \mathrm{~cm}^{-3}$ at $\sim 24: 00$ MLT. Thus, the median Na densities during the active days were mostly small compared with those during the quiet days, and those during both the quiet and active days were decreasing with MLT from dusk hours to dawn hours. Similar characteristics can be seen in those at 97-101-km heights.

On the other hand, median CNA values during the active days were $\sim 0.2 \mathrm{~dB}$ at $\sim 21: 00$ MLT and $\sim 0.5 \mathrm{~dB}$ at $\sim$ 30:00 MLT, and those during the quiet days were $\sim 0.0 \mathrm{~dB}$ at $\sim 21: 00 \mathrm{MLT}$ and $\sim 0.1 \mathrm{~dB}$ at $\sim 30: 00$ MLT. Thus, the median CNA values during the active days were mostly large compared with those during the quiet days, and that during the active days was decreasing with MLT from dusk hours to dawn hours.

To confirm significance in such differences between the median values during the quiet and active days, we did a statistical test which is the Mann-Whitney U test. Then, the median values with more than $98 \%$ probability were marked by red. It is found that most of such 
differences were significant in the cases of $\mathrm{Na}$ densities at $99-103-\mathrm{km}$ heights, but most of those at $97-\mathrm{km}$ height were not so significant. In the case of CNA, such differences were significant except for 13:00-20:00 MLT.

To make more detailed comparisons, we calculated $\mathrm{Na}$ deviations defined as $\frac{\mathrm{Na}_{\text {active }}-\mathrm{Na}_{\text {quiet }}}{\mathrm{Na}_{\text {quiet }}} \times 100$ (\%), where $\mathrm{Na}_{\text {active }}$ is the median $\mathrm{Na}$ density during the active days, and $\mathrm{Na}_{\text {quiet }}$ is the median $\mathrm{Na}$ density during the quiet days. On the other hand, CNA deviations were also calculated as $\mathrm{CNA}_{\text {active }}-\mathrm{CNA}_{\text {quiet }}(\mathrm{dB})$, where $\mathrm{CNA}_{\text {active }}$ is the median CNA during the active days, and $\mathrm{CNA}_{\text {quiet }}$ is the median CNA during the quiet days. It should be noted that we did a normalization, i.e., $\times \frac{100}{\mathrm{Na}_{\text {quiet }}}$, for the $\mathrm{Na}$ deviation, and it would be useful to compare different $\mathrm{Na}$ densities at different heights. On the other hand, the CNA deviation corresponds to $10 \times \log _{10}\left(\mathrm{P}_{\text {quiet }} / \mathrm{P}_{\text {active }}\right)$, because the definition of CNA is $10 \times \log _{10}\left(\mathrm{P}_{\mathrm{qdc}} / \mathrm{P}_{\mathrm{abs}}\right)$, where $\mathrm{P}_{\mathrm{qdc}}, \mathrm{P}_{\mathrm{abs}}$ are the received signal powers for the quiet day curve and the absorption, respectively. Then, $\mathrm{P}_{\text {quiet }}$ is the received signal power for the absorption during the quiet days, and $\mathrm{P}_{\mathrm{active}}$ is that during the active days.

Figure 5 shows MLT-height variations in the $\mathrm{Na}$ and CNA deviations. Concerning to the $\mathrm{Na}$ densities around 95-105-km heights, significant negative $\mathrm{Na}$ responses (with $>98 \%$ probability), i.e., Na decreases, can be seen during most of the period, i.e., 15:00-30:00 MLT. The $\mathrm{Na}$ deviations were $-20 \%$ at $\sim 15: 00 \mathrm{MLT}$, and $-60 \%$ at $\sim$ 29:00 MLT. Thus, amounts of the Na decreases were larger with MLT from dusk hours to dawn hours. On the other hand, most of the Na responses below $95-\mathrm{km}$ height were insignificant (with $\leq 98 \%$ probability). As for the CNA deviations, significant positive CNA responses, i.e., CNA increases, can be seen for 20:00-32:00 MLT. The CNA responses were opposite to the $\mathrm{Na}$ density responses, i.e., negative responses. The CNA deviations were $\sim 0.1 \mathrm{~dB}$ at $\sim 21: 00 \mathrm{MLT}$ and $\sim 0.4 \mathrm{~dB}$ at $\sim 32: 00$ MLT. Thus, amounts of the CNA increases were larger with MLT from dusk hours to dawn hours.

Scatter plots as well as CCs of the Na and CNA deviations are shown in Fig. 6. It should be noted that both the significant and insignificant data were included for CC calculations. It seems that the decreases in the Na deviations tended to be more severe with the increasing CNA deviations. For example, at 103-km height, the Na deviations were 0 to $-40 \%$ when the CNA deviations were $\sim 0.0 \mathrm{~dB}$, and the $\mathrm{Na}$ deviations were -20 to $-60 \%$ when the CNA deviations were $0.1-0.2 \mathrm{~dB}$. The CCs at $103-\mathrm{km}$ height have a negative peak around zero lag, and its value was about -0.6 . Similar characteristics can be seen also at $97-101-\mathrm{km}$ heights. Thus, there were clear negative correlations between the $\mathrm{Na}$ and CNA deviations.

\section{Discussion and conclusions}

As mentioned in introduction, several event-based investigations were done, and those reported conflicting results and/or suggestions regarding the response in the $\mathrm{Na}$ density to auroral activity. In some cases the Na density increased (von Zahn et al. 1987; Gu et al. 1995), and in others, it decreased (Nomura et al. 1987; Heinselman et al. 1998; Heinselman 2000; Tsuda et al. 2013; Takahashi et al. 2017). In addition, Tsuda et al. (2017) made a statistical investigation using Odin/OSIRIS data together with $\mathrm{AE}$ index, and it showed a significant decrease in the $\mathrm{Na}$ density above $\sim 95 \mathrm{~km}$ height during the geomagnetically active periods. However, statistical investigation based on comparisons with CNA data (or energetic particle information) has not been performed before the present work.

From the direct comparison between $\mathrm{Na}$ density and CNA data (indicating energetic particles), it is found that there were large variabilities in relationships between $\mathrm{Na}$ density and CNA data (see Fig. 1a). This would indicate that the energetic particle effect is not the only major contributor to Na density, and many other factors (such as seasonal, day-to-day, diurnal, and other variations) can contribute to $\mathrm{Na}$ density. To extract the effect due to CNA, we made comparisons in data distributions (or PDFs) during the larger and smaller CNA conditions (or the active and quiet conditions). Then, we found the significant decrease in the median values of the fitted PDF of $\mathrm{Na}$ density above $\sim 95 \mathrm{~km}$ height in the active condition (i.e., the larger CNA condition) (see Fig. 2b). This would suggest, for the first time, a direct effect of energetic particles on the topside of the Na layer around 95-105 km. As mentioned in introduction, the reason for the $\mathrm{Na}$ loss (cf. Heinselman 2000; Takahashi et al. 2017, and references therein) can be explained by the energetic particleinduced ionization and then the ionization-promoted charge transfer reactions, $\mathrm{Na}+\mathrm{NO}^{+} \rightarrow \mathrm{Na}^{+}+\mathrm{NO}$ and $\mathrm{Na}+\mathrm{O}_{2}^{+} \rightarrow \mathrm{Na}^{+}+\mathrm{O}_{2}$. Hence, larger energy flux of the energetic particles can cause larger ionization (as well as larger CNA), and then more charge transfer reactions by more $\mathrm{NO}^{+}$and $\mathrm{O}_{2}^{+}$ions can be promoted. In this way, it is considered that the larger $\mathrm{Na}$ loss would be induced in accordance with the larger CNA (indicating larger ionization).

As for the MLT characteristics, it is found that the CNA deviation was increasing from 18:00 MLT to 32:00 MLT (see Fig. 5c). This result would be a well-known general feature which was obtained from other riometer observations (e.g., Kavanagh et al. 2004). The CNA increase indicates enhancements of $D$ region electron densities, and then such enhancements imply more precipitation (larger energy flux) of the energetic particles (cf. Tanaka et al. 2005), which would consist of mainly 10-100-keV electrons. MLT features of such energetic 

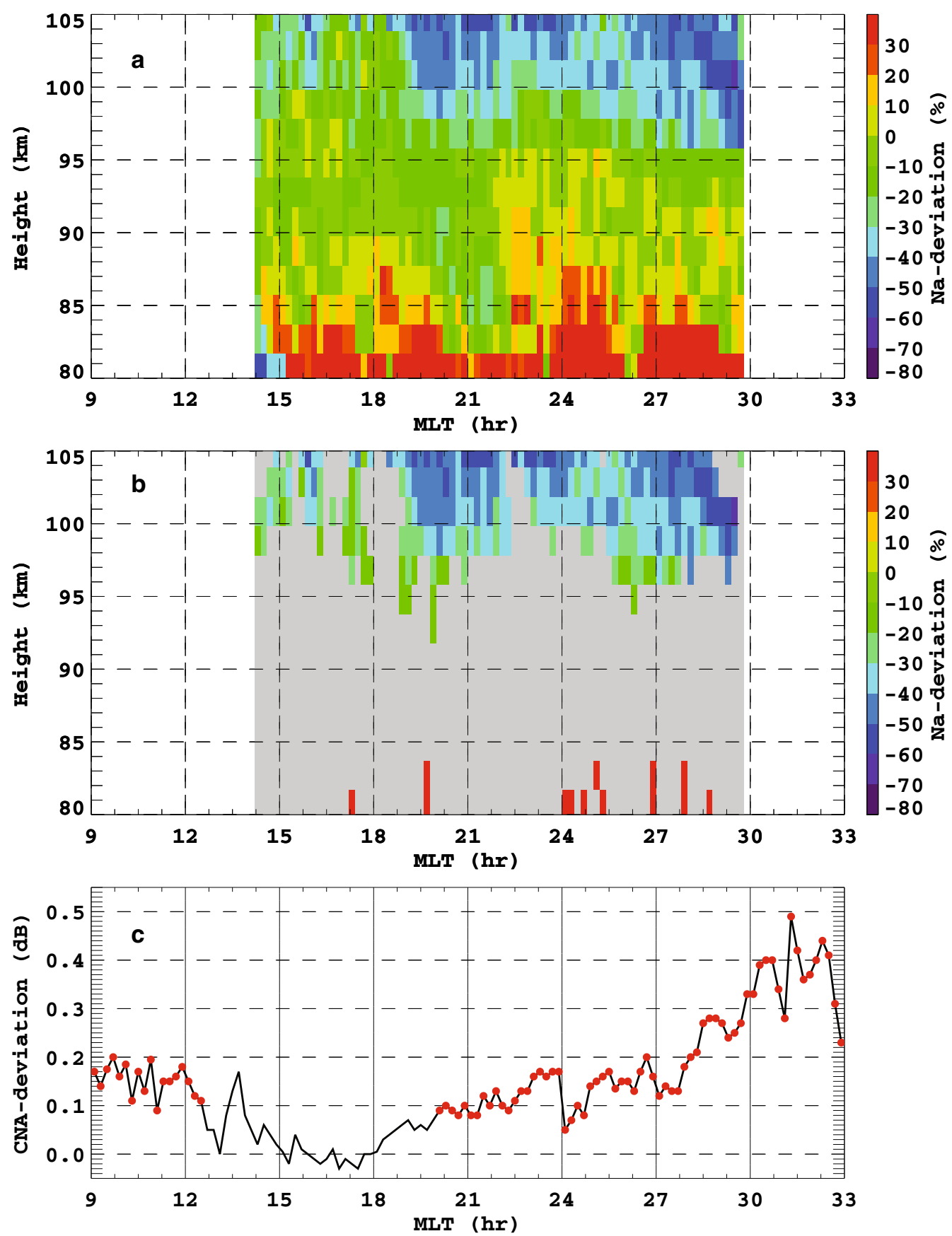

Fig. 5 a MLT-height variation in the Na deviation. b Same as a, but insignificant data ( $\leq 98 \%$ probability) are shaded by gray color. c MLT variation in the CNA deviation. Red points indicate data which have significant differences ( $>98 \%$ probability) in the median values between the quiet and active days. For both the $\mathrm{Na}$ and CNA deviations, negative values indicate decrease during the active days, and positive values indicate increase during the active days

electrons were investigated by satellite observations (Lam et al. 2010). They showed that the energy flux of energetic electrons $(>30 \mathrm{keV})$ increased during the active periods (with $\mathrm{AE}$ index of $>300 \mathrm{nT}$ ), and that the energy flux was increasing from 18:00 MLT to 30:00 MLT, i.e., from dusk hours to dawn hours. Thus, the observed MLT feature in the CNA deviation can be well explained by the MLT feature of the energy flux of the energetic electrons reported in Lam et al. (2010). In addition, Hosokawa and Ogawa (2015) showed that peak height of electron density due 

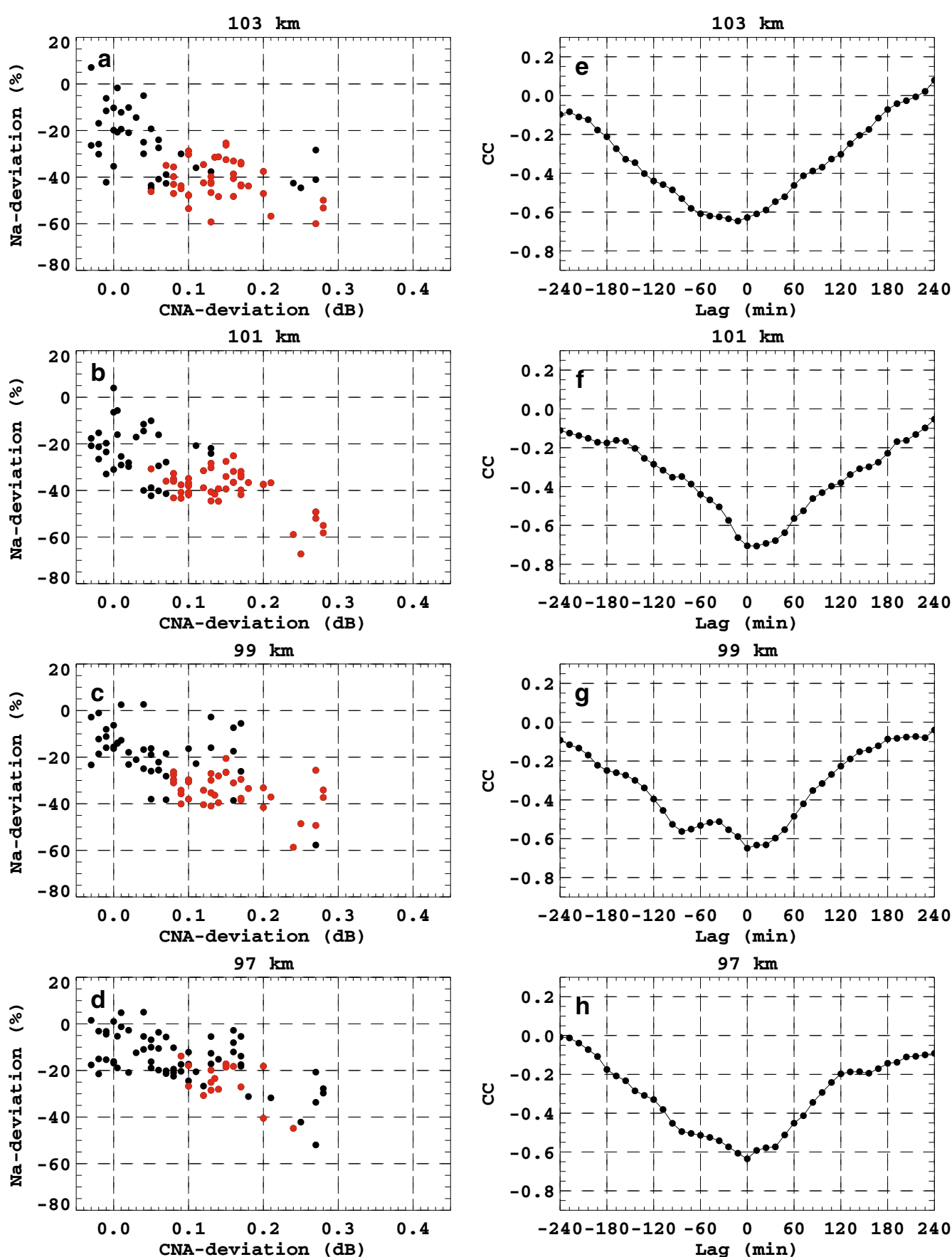

Fig. 6 a-d Scatterplots (with zero lag) of the Na and CNA deviations at 97-103-km heights. Red points indicate data which have significant differences (> 98\% probability) in the median values between the quiet and active days. $\mathbf{e}-\mathbf{h}$ The correlation coefficients (CC) between the Na and CNA deviations (derived from the cross-correlation analysis) at 97-103-km heights

to pulsating aurora was lower with MLT (from $110 \mathrm{~km}$ at 27:00 MLT to $100 \mathrm{~km}$ at 30:00 MLT), analyzing the ground-based observation data obtained at Troms $\varnothing$, Norway $\left(69.6^{\circ} \mathrm{N}, 19.2^{\circ} \mathrm{E}\right)$. Their results imply that the energy of energetic electrons become larger with MLT, and it would be also consistent with the MLT feature of the CNA deviation obtained from our statistical data analysis.

On the other hand, an importance of the present work is the statistical investigation on MLT characteristics on 
$\mathrm{Na}$ density as well as CNA based on the simultaneous data from the co-located instruments. The observed MLT characteristics in the $\mathrm{Na}$ deviations were mostly negative (i.e., decrease in Na density) above $\sim 95 \mathrm{~km}$ height during the active days (see Fig. 5b). The Na deviations were well correlated with the CNA deviations, and its CC were less than -0.6 , i.e., clear negative correlations. This would imply a strong link between them. Thus, these observed MLT characteristics in the $\mathrm{Na}$ - and CNA-deviations would be observational evidences for the $\mathrm{Na}$ loss induced by the energetic particle precipitation during geomagnetic active days, and it suggests that the effect on the $\mathrm{Na}$ layer would be more severe in dawn hours. Furthermore, the results in the MLT characteristics are well consistent with that from the direct comparison. These statistical results from the present work would be also consistent with those by Tsuda et al. (2017).

As discussed above, the main cause for the larger $\mathrm{Na}$ loss around dawn hours would be due to the larger energy flux of the energetic particles around dawn hours. Such larger energy flux around dawn hours can be coming from the magnetospheric processes such as pitch angle scattering by lower-band chorus waves (cf. Lam et al. 2010; Miyoshi et al. 2015, and references therein), but it is beyond the scope of the present work.

\section{Abbreviations \\ CC: Correlation coefficient; CNA: Cosmic noise absorption; JARE: Japanese Antarctic Research Expedition; LT: Local time; MLT: Magnetic local time; Na: Sodium; OSIRIS: Optical Spectrograph and Infrared Imager System; PDF: Prob- ability density function; PMT: Photomultiplier tube; UT: Universal time.}

\section{Acknowledgements}

The Na lidar observations from 2000 to 2002 were carried out as part of the Japanese Antarctic Research Expedition (JARE) observations. The database construction for the imaging riometer data has been supported by the IUGONET (Inter-university Upper atmosphere Global Observation NETwork) project (http://www.iugonet.org/). TTT thanks K. Nielsen at Utah Valley University for fruitful discussion.

\section{Authors' contributions \\ TTT designed the current research. TTT, RT, and KT conducted the data analy- sis, and wrote the first draft of manuscript. TDK contributed the operation in the Na lidar observations at Syowa. YT contributed the accumulation of the CNA data from the reometer observations at Syowa, and supported the data analysis related with the CNA data. All authors contributed toward interpret- ing the results, and improving the manuscript. All authors read and approved the final manuscript.}

\section{Funding}

This work was supported in part by MEXT/JSPS KAKENHI Grants, JP15H05815, JP16H01171, JP16H06021, JP17H02968, JP19H01956, and JP20K20940, by Inamori Research Grants from Inamori Foundation, by Research Grants from JGC-S Scholarship Foundation, by Research Grants from Casio Science Promotion Foundation, by the National Institute of Polar Research (NIPR) through the General Collaboration Project no. 31-3, and by the joint research program of the Institute for Space-Earth Environmental Research (ISEE), Nagoya University.

\section{Data availability}

The Na density data can be available on request to T. D. Kawahara (kawahara@cs.shinshu-u.ac.jp).The cosmic noise absorption (CNA) data at Syowa were analyzed by using Space Physics Environment Data Analysis Software (SPEDAS) (http://spedas.org/) with a plug-in software developed by Interuniversity Upper atmosphere Global Observation NETwork (IUGONET) (http:// www.iugonet.org/). The ap index data were provided at the website, National Centers for Environmental Information (NCEI), National Oceanic and Atmospheric Administration (NOAA) (ftp://ftp.ngdc.noaa.gov/).

\section{Ethics approval and consent to participate}

Not applicable.

\section{Consent for publication}

Not applicable.

\section{Competing interests}

The authors declare that they have no competing interests.

\section{Author details}

${ }^{1}$ Department of Computer and Network Engineering, University of ElectroCommunications (UEC), Chofu, Japan. ${ }^{2}$ National Institute of Polar Research (NIPR), Tachikawa, Japan. ${ }^{3}$ Department of Polar Science, The Graduate University for Advanced Studies, SOKENDAl, Tachikawa, Japan. ${ }^{4}$ Polar Environment Data Science Center, Joint Support-Center for Data Science Research, Research Organization of Information and Systems, Tachikawa, Japan. ${ }^{5}$ Department of Electrical and Computer Engineering, Shinshu University, Nagano, Japan.

Received: 6 July 2020 Accepted: 6 December 2020

Published online: 04 January 2021

\section{References}

Chu X, Papen GC (2005) Resonance fluorescence lidar for measurements of the middle and upper atmosphere. In: Fujii T, Fukuchi T (eds) Laser remote sensing. CRC Press, Florida, Boca Raton

Gu YY, Qian J, Papen GC, Swenson GR, Espy PJ (1995) Concurrent observations of auroral activity and a large sporadic sodium layer event during ANLC93. Geophys Res Lett 22:2805-2808. https://doi.org/10.1029/95GL02874

Heinselman CJ, Thayer JP, Watkins BJ (1998) A high-latitude observation of sporadic sodium and sporadic E-layer formation. Geophys Res Lett 25:3059-3062. https://doi.org/10.1029/98GL02215

Heinselman CJ (2000) Auroral effects on the gas phase chemistry of meteoric sodium. J Geophys Res 105:12181-12192. https://doi.org/10.1029/2000J D900085

Hosokawa K, Ogawa Y (2015) lonospheric variation during pulsating aurora. J Geophys Res 120:5943-5957. https://doi.org/10.1002/2015JA021401

Kavanagh AJ, Kosch MJ, Honary F, Senior A, Marple SR, Woodfield EE, McCrea IW (2004) The statistical dependence of auroral absorption on geomagnetic and solar wind parameters. Ann Geophys 22:877-887. https://doi. org/10.5194/angeo-22-877-2004

Kawahara TD, Kitahara T, Kobayashi F, Saito Y, Nomura A, She CY, Krueger DA, Tsutsumi M (2002) Wintertime mesopause temperatures observed by lidar measurements over Syowa station $\left(69^{\circ} \mathrm{S}, 39^{\circ} \mathrm{E}\right)$, Antarctica. Geophys Res Lett 29:4-1-4-4. https://doi.org/10.1029/2002GL015244

Kawahara TD, Gardner CS, Nomura A (2004) Observed temperature structure of the atmosphere above Syowa Station, Antarctica $\left(69^{\circ} \mathrm{S}, 39^{\circ} \mathrm{E}\right)$. J Geophys Res 109:D12103. https://doi.org/10.1029/2003JD003918

Kawahara TD, Kitahara T, Kobayashi F, Saito Y, Nomura A (2011) Sodium temperature lidar based on injection seeded Nd:YAG pulse lasers using a sum-frequency generation technique. Opt Express 19:3553-3561. https:// doi.org/10.1364/OE.19.003553

Lam MM, Horne RB, Meredith NP, Glauert SA, Griffin TM, Green JC (2010) Origin of energetic electron precipitation $>30 \mathrm{keV}$ into the atmosphere. J Geophys Res 115:A00F08. https://doi.org/10.1029/2009JA014619

Matuura N, Tsuda TT, Nozawa S (2013) Field-aligned current loop model on formation of sporadic metal layers. J Geophys Res Space Phys 118:46284639. https://doi.org/10.1002/jgra.50414

Miyoshi Y, Saito S, Seki K, Nishiyama T, Kataoka R, Asamura K, Katoh Y, Ebihara Y, Sakanoi T, Hirahara M, Oyama S, Kurita S, Santolik O (2015) Relation between fine structure of energy spectra for pulsating aurora electrons and frequency spectra of whistler mode chorus waves. J Geophys Res Space Phys 120:7728-7736. https://doi.org/10.1002/2015JA021562 
Nomura A, Kano T, Iwasaka Y, Fukunishi H, Hirasawa T, Kawaguchi S (1987) Lidar observations of the mesospheric sodium layer at Syowa Station, Antarctica. Geophys Res Lett 14:700-703. https://doi.org/10.1029/GL014 i007p00700

She CY, Latifi H, Yu JR, Alvares RJ II, Bills RE, Gardner CS (1990) Two-frequency lidar technique for mesospheric Na temperature measurements. Geophys Res Lett 17:929-932. https://doi.org/10.1029/GL017i007p00929

Takahashi T, Hosokawa K, Nozawa S, Tsuda TT, Ogawa Y, Tsutsumi M, Hiraki Y, Fujiwara H, Kawahara TD, Saito N, Wada S, Kawabata T, Hall C (2017) Depletion of mesospheric sodium during extended period of pulsating aurora. J Geophys Res Space Phys 122:1212-1220. https://doi. org/10.1002/2016JA023472

Tanaka Y, Ishii M, Murayama Y, Kubota M, Mori H, Yamamoto M, Kadokura A, Lummerzheim D, Desrochers J, Evans DS (2005) Comparison between CNA and energetic electron precipitation: simultaneous observation by Poker Flat Imaging Riometer and NOAA satellite. Ann Geophys 23:1555-1563. https://doi.org/10.5194/angeo-23-1555-2005

Tsuda TT, Nozawa S, Kawahara TD, Kawabata T, Saito N, Wada S, Ogawa Y, Oyama S, Hall CM, Tsutsumi M, Ejiri MK, Suzuki S, Takahashi T, Nakamura T (2013) Decrease in sodium density observed during auroral particle precipitation over Tromsø Norway. Geophys Res Lett 40:4486-4490. https ://doi.org/10.1002/grl.50897
Tsuda TT, Takahashi T, Nakamura T, Ejiri MK, Nishiyama T, Hosokawa K, Gumbel J, Hedin J (2017) Statistical investigation of Na layer response to geomagnetic activity using resonance scattering measurements by Odin/OSIRIS. Geophys Res Lett 44:5943-5950. https://doi.org/10.1002/2017GL072801

Turunen E, Verronen PT, Seppälä A, Rodger CJ, Clilverd MA, Tamminen J, Enell CF, Ulich T (2009) Impact of different energies of precipitating particles on $\mathrm{NO}_{x}$ generation in the middle and upper atmosphere during geomagnetic storms. J Atmos Sol Terr Phys 71:1176-1189. https://doi. org/10.1016/j.jastp.2008.07.005

von Zahn U, von der Gathen P, Hansen G (1987) Forced release of sodium from upper atmospheric dust particles. Geophys Res Lett 14:76-79. https://doi. org/10.1029/GL014i001p00076

Yamagishi H, Fujita Y, Sato N, Nishino M, Stauning P, Liu R, Saemundsson $T$ (2000) Interhemispheric conjugacy of auroral poleward expansion observed by conjugate imaging riometers at $67^{\circ}$ and $75^{\circ}-77^{\circ}$ invariant latitude. Adv Polar Upper Atmos Res 14:12-33

\section{Publisher's Note}

Springer Nature remains neutral with regard to jurisdictional claims in published maps and institutional affiliations.

\section{Submit your manuscript to a SpringerOpen ${ }^{\circ}$ journal and benefit from:}

- Convenient online submission

- Rigorous peer review

- Open access: articles freely available online

- High visibility within the field

- Retaining the copyright to your article

Submit your next manuscript at $\boldsymbol{\nabla}$ springeropen.com 